\title{
Integrating behavioral and social sciences components into a competency-based MD program curriculum: A qualitative study on opinions of faculty members
}

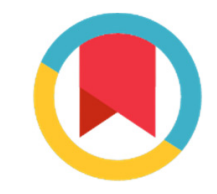

\author{
Shahnam Sedigh Maroufi ${ }^{1}$, Shoaleh Bigdeli ${ }^{1}$, Ladan Fata ${ }^{1}$, Seyed Kamran Soltani Arabshahi ${ }^{1 *}$
}

Received: 19 Dec 2015

Published: 01 Mar 2017

\begin{abstract}
Background: Behavioral, social, psychological and biological factors influence health and disease; and, to achieve professional competency, physicians should be knowledgeable about their society and its inhabitants' behavior. This knowledge will help physicians to become competent in communication, professional behavior, self-awareness, ethical reasoning, and understanding cultural and social differences. In this regard, this research is an attempt to explore perspectives of medical faculty members on necessity of integrating Behavioral and Social Sciences (BSS) components into the medical curriculum.

Methods: In this qualitative study, data were collected by semi-structured interview and observation of participants who were recruited from educational departments of faculty of medicine of Iran University of Medical Sciences. 12 faculty members were interviewed individually and were ask about their experiences and perspectives on integration of BSS subject matters into medical curriculum. Data were analyzed using content analysis.

Results: The six following themes were emerged from data analysis: "physician-patient interaction", "medical culture", "facilitating behavior change", "socio-cultural issues", "mind-body medical experience" and "physician interaction with health care system".

Conclusion: The results revealed that "physician-patient interaction" was the most prominent among the emerged themes. The participants emphasized communication, professionalism, social accountability, and socio-cultural-psychological aspects.
\end{abstract}

Keywords: Behavioral and Social Sciences, Curriculum, Competency, Medical Student, Faculty Member, Qualitative Research

Copyright@ Iran University of Medical Sciences

Cite this article as: Sedigh Maroufi S, Bigdeli S, Fata L, Soltani Arabshahi SK. Integrating behavioral and social sciences components into a competency-based MD program curriculum: A qualitative study on opinions of faculty members. Med J Islam Repub Iran. 2017 (3 Mar);31:17. https://doi.org/10.18869/mjiri.31.17

\section{Introduction}

Although the role and significance of behavioral and social sciences (BSS) in medical education and practice is no longer disputed, BSS education is still highly problematic all over the world. Numerous barriers have to be overcome for appropriate integration of BSS into the medical curriculum. The dominance and biases of the widely held biomedical worldview of Western medicine is cited as a major impediment in achieving the objectives of BSS

Corresponding author: Dr Seyed Kamran Soltani Arabshahi, soltarab@iums.ac.ir

1. Center for Educational Research in Medical Sciences, Department of Medical Education, Faculty of Medicine, Faculty Member of Iran University of Medical Sciences, Tehran, Iran in medical education. Moreover, the biomedical mindset is often not quite compatible with BSS (1).

Behavioral, social, psychological and biological factors influence health and disease $(2,3)$. It is broadly accepted that all physicians should know the concepts of BSS to manage patients by application of multifaceted and holistic methods and not just treating symptoms of diseases (1, $4,5)$. The multidisciplinary perspective of BSS, provides

$\uparrow$ What is "already known" in this topic:

Physicians should know the concepts of behavioral and social sciences to manage patients by application of multifaceted and holistic methods. Thus, understanding strategies of complementary and alternative medicine, and probable negative impacts are important.

\section{$\rightarrow$ What this article adds:}

During a qualitative study, six themes (physician-patient interaction, medical culture, facilitating behavior change, sociocultural issues, mind-body medial experience and physician interaction with the health care system) and 16 sub-themes supported the importance of medical teachers, students, and staff competency in behavioral and social factors. 
medical students with an understanding of patient as a part of extensive social context that influences biological processes and is under its influence (6). Although the aim of behavioral sciences is to apply knowledge, skills, concepts and attitudes to elaborate human behavior, social sciences study human social dimensions (7).

Mind-body interactions and the behavioral impacts on health and diseases are vital concepts to which medical students must be exposed. They need to understand how personal background and beliefs influence rendering care to patients and their own health, how to interact with patients and their families, and how cultural issues influence health care (8).

On the other hand, interest of patients to mind-body medicine encourages them to use complementary and alternative medicine to maintain their own heath or treat diseases regardless of their social class. Therefore, to interact with health care system, understanding strategies of complementary and alternative medicine, and their probable negative impacts are of prime importance (9).

To gain mastery over biomedical knowledge, it is necessary for medical students to acquire meta-skills that promote learning. In clinical settings, to gain benefit from this medical knowledge, students should manage their feelings, stress and competitive demands. In this regard, BSS deepens individual capacities that improve skills and increase self-awareness $(10,11)$.

Medical education institutes seek to promote their traditional formal curriculum by development and assessment of competency of medical students including BSS competencies in communication, self-awareness, professionalism and moral reasoning (15-17).

Integration of BSS into curriculum of general medicine is necessary for various reasons some of which are as follows: changes in the main causes of mortality, important role of behavior modification in prevention and treatment of diseases such as heart diseases, cancer, cerebro-spinal diseases, accidents, chronic obstructive pulmonary diseases, pneumonia, influenza, diabetes, suicide, liver disease, and HIV (3); cultural and ethnic diversity; professional awareness of risks of miscommunications, and cultural consideration; communication, negotiation and promotion of motivations (18).

The application of BSS principles in medical education considers physician-patient relationship, complex systems of health care, social policies and public health (8). In addition, in an educational environment, BSS offers necessary instruments for professional development, guides the education process, and supports a humane educational environment (19). Also, BSS improves social accountability through reinforcing leadership skills of taking social responsibility and understanding the constantly changing health demands of the society, region and the nation (15, 20).

Association of American Medical Colleges (AAMC) emphasizes that medical colleges have the specific task of educating medical students and they are socially responsible for the health of community (10). In this regard, World Federation for Medical Education (WFME) emphasizes the medical education indexes including BSS, and suggests that the quality of educational programs of medical courses be evaluated according to them (20).

BSS competency in medical sciences in the entire period of the medical program is a multi-stage process that integrates cognitive, behavioral and social dimensions. Physicians learn from formal and informal sources during their professional life. And a useful framework to assess their formal and informal experiences is to focus on their competencies and capabilities (15).

Now, the emphasis is on an integrated program that includes BSS components. Despite the fact that the BSS contents of curriculums in medical colleges are increasing, only a few number of colleges integrate BSS in Medical Education successfully. A part of increasing load of BSS in curriculum of medical colleges is due to the request of the Liaison Committee on Medical Education (LCME), which indicates that accreditation of curriculums of medical colleges include social, economic and behavioral themes (8).

Some medical colleges lack standardized BSS curriculum content and follow their own teaching methods. LCME and the accreditation bodies of medical colleges in Canada and the U.S. pursue a number of specific subjects related to BSS in the curriculum of medical students, but they did not specify, BSS teaching methods, hours required to teach BSS and to be covered BSS subject matters. They only stated that in addition to basic and clinical sciences, the curriculum should include social, economic and behavioral components. Consequently, each medical college flexibly designs programs that fit its curriculum (21).

To manage the load of medical college general course content, faculty members may limit the components to basics or must knows that each medical student needs to understand (22). Since the approach to include the subjects to medical programs is not specified by LCME, each medical college covers BSS contents according to its aims and goals (23).

In Iran, due to growing ethnic and cultural diversity, new medical opportunities and challenges have emerged; therefore, physicians are required to be equipped with improved health management skills to manage this diverse population $(18,24-26)$.

In February 2006, Iran Ministry of Health and Medical Education announced certain approvals about the following subjects with a particular attention to BSS: The attitude and behavior changes compatible to the standard written indicators of the general education with an emphasis on medical, ethical, and professional behavior, social accountability, effective communication, patient education, team-working and monitoring the society.

In the Iranian curriculum of general medicine, the educational program has some weaknesses in regard to BSS including patient-oriented instead of health-oriented attitude and lack of systematic attention to some BSS topics and their consequences.

In this regard, the study aimed to shed light on BSS importance and integrating it into the educational program of general medical courses. 


\begin{tabular}{|c|c|c|}
\hline Codes & Sub-themes & Themes \\
\hline $\begin{array}{l}\text { Establishment of humane communication, communication as an art, active listening, under- } \\
\text { standing the patient, talking with the patient, trust building, communication as a pivot, role of } \\
\text { psychological factors in establishment of relation, respecting the patient's culture, weakness } \\
\text { in teaching communicative skills, gaining dialogue techniques, importance of the scope of ki- } \\
\text { netic-mental learning skills in acquisition of communicative skills }\end{array}$ & $\begin{array}{l}\text { Basic communicative } \\
\text { skills }\end{array}$ & $\begin{array}{l}\text { Physician-patient } \\
\text { interaction }\end{array}$ \\
\hline $\begin{array}{l}\text { Establishing good relations with the elderly and children, the role of translator in specific occa- } \\
\text { sions, establishing good relations in different cultural occasions, professional link with col- } \\
\text { leagues, competency of cultural understanding, respecting patient's beliefs, gaining patients' } \\
\text { trust in treatment cadre, the positive role of language in establishing good relations }\end{array}$ & $\begin{array}{l}\text { Complex communica- } \\
\text { tive skills }\end{array}$ & \\
\hline $\begin{array}{l}\text { Treating patients with different personalities, giving bad news, asking sensitive questions, tak- } \\
\text { ing the personal and gender history of the patient }\end{array}$ & $\begin{array}{l}\text { Difficult communica- } \\
\text { tive skills }\end{array}$ & \\
\hline
\end{tabular}

\section{Methods}

Ethical considerations of the study were approved by Ethics Committee of Iran University of Medical Sciences. In addition, the study participants were assured about the anonymity of data and signed a written informed consent form.

The study started from August 2013 and continued for 17 months. The study settings were faculty of medicine and teaching hospitals affiliated to Iran University of Medical Sciences.

In this content analysis study, the study participants who were faculty members of basic and clinical Sciences of medical school of Iran University of Medical Sciences with educational and administrative experience were interviewed individually about application of BSS in medical curriculum.

Semi-structured interviews were conducted during two months because of the excessive workload of the interviewees. Each interview lasted 60-75 minutes.

Sampling was purposeful and snowballing continued till data saturation (12 interviews); in other words, when no new data emerged. Some of the interview guided questions were as follows:

- Considering your experiences about the role of human behavior and interaction in rendering patient care, how do you evaluate role of physicians?

- How background and beliefs of medical students influence their own health and rendering care to patients?

- How does a patient establish a relationship with her/his physician?

- How does culture affect health care delivery?

- "What is the role of patient support systems or executive supportive mechanisms in patient management?" "What are the emotional, cognitive and social consequences of diseases, and how do they influence the clinical results?"

The interviews were recorded and transcribed verbatim. Then, the transcripts were imported to MAXQDA 10 software for data analysis.

The transcripts were read and re-read for several times by the first author to determine the meaning units. In the next stage, the units were summarized and converted into codes. According to their similarities and dissimilarities, codes were categorized into sub-themes. Then, the re- searchers reached consensus on the emerged themes. In addition, one of the researchers attended educational environments and observed the educational processes and learners' interactions with patients or teachers on the topics related to BSS and the observation data/memos converted into codes.

Finally, the collected data was presented to an expert panel of BSS in Iran University of Medical Sciences to be verified.

\section{Data authenticity}

In this research, several methods and data collection sources were used (triangulation).

To ensure validity (trustworthiness), the findings were confirmed by the study participants (member-check), and to maximize reliability, data was analyzed by one of the researchers and the analysis was re-checked by the research team. Moreover, thick descriptive data was collected and research findings were compared to the available literature to specify similarities and dissimilarities.

\section{Results}

Using content analysis, from the codes extracted from memos, interviews and observation, six themes were extracted which are presented as follows.

\section{Physician-patient interaction}

This theme includes three sub-themes of basic, complex and problematic communication skills (Table 1).

Based on the results, communication skills and the role of physician-patient interaction were the first priority for the participants. Moreover, most participants referred to the following factors as the most important elements in providing appropriate treatment for patients: psychological factors, rapport for managing patient's emotions and concerns, socio-cultural competency of physicians in establishing an appropriate relationship with patients, respecting the patients' culture, physician's active listening skills, communication skills, physician as the crucial agent in developing appropriate relationships with patients, teaching communication skills to faculty, time-allocation for effective doctor-patient relationship, teaching communication skills to colleagues, and physician appropriate interaction. 
Table 2. Medical culture: codes and sub-themes

\begin{tabular}{|c|c|c|}
\hline Codes & Sub-themes & Themes \\
\hline $\begin{array}{l}\text { Ethical awareness, merit of professional ethic, professional ethic has a humane dimensions, the posi- } \\
\text { tive role of individual ethic background of the physician in the treatment of patient, professional } \\
\text { behavior is the physician's capital, medical career is a humane science, having a philosophical } \\
\text { view towards medicine, considering patients' values, the positive role of physicians' beliefs and } \\
\text { spiritual issues in the effectiveness of treatment, the association of BSS with the complaint from } \\
\text { the medial society, a mechanical view towards the patient, a health-oriented view towards treat- } \\
\text { ment, physician's pride an obstacle vis-à-vis success }\end{array}$ & $\begin{array}{l}\text { Professional } \\
\text { behavior }\end{array}$ & Medical culture \\
\hline $\begin{array}{l}\text { A very emotional treatment of the patients, philanthropy, the basic role of the physicians' personality } \\
\text { in the treatment of the patients, previous mentality of the patients towards the physicians' personal- } \\
\text { ity, cultural backgrounds, life experiences }\end{array}$ & $\begin{array}{l}\text { Physicians' } \\
\text { personal values }\end{array}$ & \\
\hline $\begin{array}{l}\text { Knowledge about sources accessible to the patient and society, practical knowledge about types of } \\
\text { suggested interventions, familiarity with insurance policies }\end{array}$ & Patient support & \\
\hline $\begin{array}{l}\text { Paying attention to the society needs, competency to grasp the socio-economic issues, the positive } \\
\text { role of physicians' beliefs in accountability, understanding the constantly changing health de- } \\
\text { mands of the society, reinforcing the social responsibility, learning leadership skills }\end{array}$ & $\begin{array}{l}\text { Social account- } \\
\text { ability }\end{array}$ & \\
\hline Codes & Sub-themes & Themes \\
\hline $\begin{array}{l}\text { Providing training to prevent risky behaviors, detecting behaviors related to causes of morbidity and } \\
\text { mortality, familiarity with the role of health care providers' risky behaviors, consulting role, famili- } \\
\text { arity with the theories of behavior change, creation of motivation for student behavior change }\end{array}$ & $\begin{array}{l}\text { Patient's behavior } \\
\text { change }\end{array}$ & $\begin{array}{l}\text { Facilitating the } \\
\text { behavior change }\end{array}$ \\
\hline $\begin{array}{l}\text { Educating the students about cognitive theories of social learning, encouraging student behavior } \\
\text { change, the positive role of informal education in behavior change, the poverty in role modeling in } \\
\text { the education chain, the positive role of professors in role modeling }\end{array}$ & $\begin{array}{l}\text { Student's behav- } \\
\text { ior change }\end{array}$ & $\begin{array}{l}\text { Socio-cultural } \\
\text { issues }\end{array}$ \\
\hline $\begin{array}{l}\text { Patient's occupation and income, race differences, ethnicity and health of the patients, competency to } \\
\text { grasp the social and psychological variables, attending to behavioral and social issues of the pa- } \\
\text { tients, patient education }\end{array}$ & Social differences & \\
\hline $\begin{array}{l}\text { Paying attention to patients' values, mixing culture of care with beliefs, knowing the cultural bed } \\
\text { ground of the patients, the role of culture in the description of disease symptoms, family and socio- } \\
\text { cultural variables, familiarizing students with cultural issues upon their entrance into the university, } \\
\text { understanding economic-cultural variables, respecting patients' beliefs, impact of ethnic diversity } \\
\text { in detecting and treating the disease }\end{array}$ & Socio-Cultural & \\
\hline $\begin{array}{l}\text { Understanding the efficiency and safety of alternative and complementary treatment in local commu- } \\
\text { nities, using traditional medicine in uncontrollable pains, supporting the complementary and alter- } \\
\text { native medicine for educating medical students, agreement with complementary medicine, deletion } \\
\text { of superstitions from complementary medicine, traditional medicine as a help to the modern medi- } \\
\text { cine, necessity of providing educational course in connection with traditional medicine, supporting } \\
\text { the complementary and alternative treatment strategies, providing training about medical interven- } \\
\text { tions and symptoms resulting from the consumption of traditional medicines }\end{array}$ & $\begin{array}{l}\text { Complementary } \\
\text { and alternative } \\
\text { medicine }\end{array}$ & \\
\hline
\end{tabular}

One of the clinical faculty members said: "Physicians are weak in establishing rapport in diverse cultural opportunities". Another clinical faculty member stated: " $\mathrm{Pa}$ tient's trust promotes treatment process. It is necessary to respect patient's beliefs, values and culture to increase his/her trust in treatment cadre". In addition, the participant mentioned that medical students should acquire the necessary skills to successfully manage difficult interactions when taking the patient's history and during the treatment.

\section{Medical culture}

Professional behavior, physician's personal values, social accountability and patient support were important for the participants (Table 2).

Most participants mentioned professionalism, the positive role of ethnic background of the physician, the impact of the clinical teacher on students as a role model, clinicalteacher philosophical and humane view towards medicine, working in health teams, consideration of patient's beliefs and values, paying attention to patient's mental, social and spiritual dimensions.

Another participant mentioned, "Paying attention to the BSS and having a humane view towards patient will reduce the rate of complaints from the medical community".
Moreover, participants declared that considering professional ethics in medical curriculum as a competency is absolutely necessary. In addition, they believed that patients' preconception about ideal physicians is crucially important in doctor-patient relationship. In this respect, one of the participants stated, "Sometimes a patient has a dream about an imaginary physician, which plays an important role in doctor-patient interaction and treatment process".

Physicians are supposed to be accountable for the health of individual and society, and their accountability can be promoted by reinforcing their social accountability skills and their understanding of the constantly changing health needs of the society and the individual patient, supporting the patient through accessible resources, and being knowledgeable about patient management and insurance policies.

\section{Facilitating behavior change}

The two sub-themes of patient behavior change and student behavior change are presented in Table 3 .

Some of participants referred to detecting the behaviors related to causes of morbidity and mortality, preventing risky behaviors, acquisition of consultation skills, familiarity with roles of healthcare providers, and provoking 
Table 4. Mind-body experience and "physician- healthcare system interaction: codes and subthemes

\begin{tabular}{|c|c|c|}
\hline Codes & Sub-themes & Themes \\
\hline $\begin{array}{l}\text { The role of behavioral and social factors in body physiology change, internal links of hemostatic } \\
\text { systems, the ability to talk to patients with mental and physical disorders, the relation between } \\
\text { chronic distress and social support, reducing patient stress, the impact of social places in } \\
\text { emerging stress generating factors, supporting the mind-body medicine }\end{array}$ & $\begin{array}{l}\text { Biological intermedi- } \\
\text { aries between health } \\
\text { and social and mental } \\
\text { factors }\end{array}$ & $\begin{array}{l}\text { Mind-body medi- } \\
\text { cal experience }\end{array}$ \\
\hline Multi-treatment for pain control, killing the pain without medicine, orientations in pain treatment & Mental aspects of pain & \\
\hline $\begin{array}{l}\text { Accountability and awareness towards bed ground and larger systems of the health care system, } \\
\text { interdisciplinary cooperation, interaction with the health care systems, physicians' commitment } \\
\text { towards health system, participation with the members of different systems for an ideal care of } \\
\text { patient, familiarity with different types of systems of service presentation, allocation of finan- } \\
\text { cial sources, health services, forecasting the reaction of the patients to complex and costly } \\
\text { treatment plans, the role of economic incentives in connection with the health and behavior of } \\
\text { patients }\end{array}$ & Health care's systems & $\begin{array}{l}\text { Patient's interac- } \\
\text { tion with health } \\
\text { care }\end{array}$ \\
\hline $\begin{array}{l}\text { Lack of success in establishing relations, deficiency in equipment, unsuitable care, using irregular } \\
\text { measures or methods, insufficient treatment follow-ups, error in implantation of a function, lab } \\
\text { tests or process, delay in detection }\end{array}$ & System errors & \\
\hline
\end{tabular}

motivation for behavior change.

A faculty member of Basic Sciences mentioned, "Rolemodeling is weak in the educational stream" and reminded the positive role of informal education in behavior change amongst students. Another clinical participant stated, "More specialized medicine has decreased appropriate contact between clinical teachers and students in educational environments".

Meritocracy in faculty selection as a role-model in educational settings was among other experiences of the study participants. In addition, empowering faculty members can be effective in students' behavior change. A faculty member of Basic Sciences asserted, "Faculty empowerment on BSS including familiarity with cognitive theories of social learning, attending educational workshops and positive role of on time feedback will enhance student's education". He further stated that the education system should emphasize on the value of BSS-related subjects and help its full development by positive incentives. To achieve the above mentioned objectives collaboration with psychology, sociology and social medicine experts is highly recommended.

\section{Social and cultural issues}

Another theme with three sub-themes of social differences, cultural competency and alternativecomplementary medicine is presented in Table 3 .

The role of racial differences and ethnicity in diagnosing and treating patients, establishing a relationship with patients from different ethnic backgrounds, role of patient's occupation and income, understanding social contexts, positive role of language in establishing rapport and presenting diagnostic and curative services, considering cultural diversity and describing symptoms of diseases, and understanding the efficiency and safety of alternative treatment methods in local communities were amongst the other issues.

One of the clinical participants said, "The traditional and complementary medicine can help modern medicine in cases when modern modalities are not effective, for example to meditation for patients with uncontrollable pains." Modern medicine can establish a productive dialogue with traditional medicine if superstitious ideas are removed from traditional medicine". Moreover, another faculty member said, "Inclusion of Iranian traditional medicine in courses in medical curriculum is necessary for medical students to become familiar with traditional medical interventions and treatment".

\section{Mind-body medical experience}

The next theme with two sub-themes is biologic intermediaries between health and social mental factors and mental aspects of pain (Table 4). The interviews referred to the role of behavioral and social factors in changes of physiology, homeostasis, the ability to communicate with patients who suffer from mental and physical disorders, the relation between chronic distress and patient stress reduction. Also, most of the study participants emphasized the necessity of inclusion of mind-body medicine in the medical curriculum.

\section{Physicians' interaction with the health care system}

The last emerged theme with two sub-themes is health care system and system errors (Table 4). In this respect, participants mentioned the importance of awareness and accountability of physicians to health care system. They have experienced interaction and interdisciplinary cooperation, physician's commitment to treatment and health systems, role of economic motivation in health, allocation of financial resources, impact of costs on the patients and on the related organization, diversity of treatment methods, life opportunities for the patients and the ability to screen the patients.

A number of participants believed that physicians should gain the necessary knowledge about the rules and regulations when faced with the following problems: Lack of success in establishing rapport with the patient, equipment deficiency and consequences of insufficient follow-ups, inappropriate care and medical errors in ordering lab tests or performing processes.

In addition, a change in the paradigm of educational system and the existing traditional scenes of medical education seems to be necessary. The high volume of biomedical curriculums caused lack of attention to other dimensions of health including communications, medical ethics and socio-cultural differences of patients. In such a context, empowerment of professors with BSS seems essential. 
Finally, an expert panel including educational executives reached consensus to include BSS content into general medicine curriculum.

\section{Discussion}

The most noticeable theme described by the participants in regard to Behavioral and Social Sciences was "physician-patient interaction". Participants expected physicians to establish communication, professional behavior, social accountability, and to understand socio-cultural and psychological issues and to be actively involved in the broader scene of health care system.

This finding is in agreement with the results of the Institute of Medicine (IOM). And, the results of the study revealed that physicians should acquire basic communicative skills for precise history taking, establishing a good therapeutic relationship with the patient and involving the patient in the trend of joint decision-making $(17,27,28)$.

Moreover, the emerging themes of the study, including physician-patient interaction, medical culture, facilitating behavior change, considering social and cultural issues, mind-body medical experience and physician interaction with health care system are compatible with IOM report, which indicated that medical colleges should expose medical students to BSS programs that is based on consideration of social and cultural issues in health care. Nonetheless, the topics related to this domain are still not clarified $(8,18)$.

Moreover, participants believed that it is necessary to consider cultural issues in medical curriculum by emphasizing BSS; also, most of them emphasized the introduction of professional behavior subjects, humane view towards medicine and social accountability, and believed that education of physicians lack ample focusing on the mentioned subjects that must be considered in the formal and informal curriculum of medical students. Coulehan and Schroder et al. 2003 study revealed that some faculty members believed medical education does not educate socially accountable physicians. In other words, medical colleges social responsibility for public health improvement is not fulfilled $(20,29,30)$.

In addition, the study of Bellini and Zinn(2001) showed that the inclusion of BSS in the curriculum of medical students promotes humane medical actions, enhance major coping strategies of the students/patients, and provides a framework for integration and confirmation of philanthropic principles, which neutralize unwanted hidden curriculum $(4,31,32)$.

In this research, the study participants had a positive attitude to achieve competency to modify patients' behavior, and to detect their mortality and risky behaviors. Consultation skills competency and ability to motivate patients, help medical students to change patients' behavior.

In this study, another major concern of participants was faculty's knowledge and skills in changing student' behavior. They pointed out the importance of role modeling of clinical teachers in training of future doctors. They also mentioned the importance of faculty knowledge about cognitive social theory, and influential role of BSS in changing students' behavior, which indicate the positive attitude of participants toward of BSS inclusion into medical curriculum. McGinnis et al. (1993) and Satterfield et al. (2004) have also indicated that changes in the life style and certain behaviors (such as unhealthy diet, alcohol abuse, and risky sexual behavior) can increase the life expectancy in some diseases such as heart diseases, cancer, cerebro-spinal diseases, accidents, suicide, chronic obstructive pulmonary diseases, etc. $(3,26)$.

The other extracted theme, social and cultural issues, was considered by the participants as a competency in a medical curriculum. Understanding the race and ethnic differences, attention to economic, social and psychological variables and patient values were among their outstanding experiences. Crawley and Satterfield (2004) found that the growing ethnic and cultural diversity has made the health experts facing new challenges and opportunities, leading them to develop better skills to manage health related issues and to communicate well with diverse populations $(17,25,33)$.

Smedley et al. (2003) also showed that social factors such as race, ethnicity, education, income and occupation correlate to morbidity, mortality, and disability. $(12,14)$.

Participants supported the presentation of courses related to traditional and complementary medicine and considered it as an aid to the modern medicine. They believed that considering the tendency of individuals to use mind-body medicine, and to delete complementary medicine superstitions is an alternative in cases that modern therapies are not effective. Furthermore, it was suggested that to familiarize medical students to medical interventions, effects and adverse effects of traditional drugs consumption, to design and implement an educational course on traditional medicine is recommended.

Kaptchuk et al. showed that individuals with different occupations showed tendency towards different complementary and alternative treatment strategies to maintain their health and treat their disease. Thus, to interact with alternative modalities, it may be necessary to elaborate the useful strategies of complementary and alternative medicine (such as meditation) (9).

\section{Mind-body medical experience}

The mind-body medical experience was another emerged theme. Here, most of the participants believed that physiology of the body is affected by the behavioral and social factors. The capability of medical students in detecting mental and physical disruptions and orientation towards patients' stress reduction were emphasized, and they supported mind-body medicine and inclusion of related subjects in the medical curriculum. The importance of stress in the pathogenesis of diseases could be highlighted by a report published by Smith and Anderson showing that stress is positively correlated with a broad type of diseases and health behaviors such as cardiovascular diseases, chronic obstructive pulmonary diseases, smoking and possible cancer $(34,35)$.

\section{Physician interaction with health care team}

This emerged theme indicates that the study participants emphasized on competency of physician's accountability 
towards the broad scope of the health care system, necessitating awareness of health economy, interdisciplinary cooperation and interaction, developing a skill in allocation of financial resources and supporting the patient, helping patients to find additional resources, understanding the costs of health care and awareness of system errors such as performance errors, prescription errors, delay in diagnosis, and unusual treatments.

Cuff et al. (2004) showed that social factors such as health and economic policy are effective in providing ideal care for patients. These subjects can present some information on physicians' attitude towards prevention, diagnosis and patient care. Physicians are also in need of knowledge and skill about providing care to an aging population. For this purpose, they should understand the mutual effect of behavioral and social factors (such as diet, sports, and social and family support) and their role which to prevent a disease or to delay its progress $(8,16)$.

\section{Study limitations}

Occupational involvement of clinical physicians was a burden and to arrange a suitable time for interview was difficult. Further, faculty reluctance to employ new methods such as small group discussion and problem-based learning that are suitable to teach BSS content was a guard against this topic

\section{Conclusion}

Medical training programs have employed a variety of organizational and theoretical frameworks as vehicles to expand BSS-based education. Among these, medical education mission could not be accomplished unless there is an understanding of the role of behavioral and social factors, a useful framework to merge BSS in formal and informal curricula, and focusing on competency and capability of medical students, which emphasizes addition of BSS content into formal curriculum and educational settings.

In this study, 6 themes (physician-patient interaction, medical culture, facilitating behavior change, sociocultural issues, mind-body medial experience and physician interaction with the health care system) and 16 subthemes were emerged, which supports the importance of medical teachers, students, and staff competency in BSS.

\section{Acknowledgements}

The authors would like to express their gratitude to faculty members and experts of Center for Educational Research in Medical Sciences (CERMS), Faculty of Medicine and staff of Teaching hospitals affiliated to Iran University of Medical Sciences.

In addition, this paper is part of a $\mathrm{PhD}$ thesis granted by research deputy of Iran University of Medical Sciences (grant number 2207).

\section{Conflict of Interests: Declared none.}

\section{References}

1. Isaac M, Rief W. Role of behavioural and social sciences in medical education. Curr Opin Psychiatry. 2009;22(2):184-7.
2. National Center for Health Statistics (NCHS). Health, United States, 2003: chartbook on trends in the health of Americans. Hyattsville, MD: NCHS; 2003. Available from: http://www.cdc.gov/nchs/data/hus/hus03.pdf.

3. McGinnis JM, Foege WH. Actual causes of death in the United States. J Am Med Assoc. 1993;270(18):2207-12.

4. Russell A, Van Teijlingen E, Lambert H, Stacy R. Social and behavioural science education in UK medical schools: current practice and future directions. Med Edu. 2004;38(4):409-17.

5. Litva A, Peters S. Exploring barriers to teaching behavioural and social sciences in medical education. Medl Edu. 2008;42(3):309-14.

6. Institute of Medicine (IOM). Medical education and societal needs: a planning report for health professions. Washington DC: National Academy Press; 1983.

7. Peters S, Livia A. Relevant behavioural and social science for medical undergraduates: a comparison of specialist and non-specialist educators. Med Edu. 2006;40(10):1020-6.

8. Cuff PA, Vanselow NA, editors. Improving medical education: enhancing the behavioral and social science content of medical school curricula. Washington DC: National Academies Press; 2004.

9. Kaptchuk TJ, Eisenberg DM. Varieties of healing. 1: Medical pluralism in the United States. Annal Intern Med. 2001;135(3):189-95.

10. McCurdy L, Goode LD, Inui TS, Daugherty RM, Wilson DE, Wallace $A G$, et al. Fulfilling the social contract between medical schools and the public. Acad Med. 1997;72(12):1063-70.

11.Yusoff MSB, Esa AR. Stress management for medical students: A systematic review: INTECH Open Access Publisher; 2012.

12.Smedley BD, Stith AY, Nelson AR, Institute of Medicine (U.S.). Committee on Understanding and Eliminating Racial and Ethnic Disparities in Health Care. Unequal treatment: confronting racial and ethnic disparities in health care. Washington DC: National Academy Press; 2003c.

13. Geiger HJ, Borchelt G. Racial and ethnic disparities in US health care. Lancet. 2003;362(9396):1674.

14. Farley JH, Hines JF, Taylor RR, Carlson JW, Parker MF, Kost ER, et al. Equal care ensures equal survival for African-American women with cervical carcinoma. Cancer. 2001;91(4):869-73.

15. Litzelman DK. Education for competencies in social \& behavioral sciences. In: Feldman MD, Christensen JF, editors. Behavioral medicine: A guide for clinical practice. 3rd ed: McGraw-Hill Medical; 2008.

16. Tiffin PA, Finn GM, McLachlan JC. Evaluating professionalism in medical undergraduates using selected response questions: findings from an item response modelling study. BMC Med Edu. 2011;11(1):43.

17. Van Rijssen $H$, Schellart A, Berkhof $M$, Anema J, Van der Beek A. Stereotyping of medical disability claimants' communication behaviour by physicians: towards more focused education for social insurance physicians. BMC Pub Health. 2010;10(1):666.

18.Zanetti ML, Dinh A, Hunter L, Godkin MA, Ferguson W. A longitudinal study of multicultural curriculum in medical education. Int J Med Edu. 2014;5:37.

19. Wear D, Castellani B. The development of professionalism: curriculum matters. Acad Med. 2000;75(6):602-11.

20. Education WFfM. Basic Medical Education: WFME Global Standards for Quality Improvement. Copenhagen. 2003;18(1).

21. Liaison Committee on Medical Education (LCME). Functions and structure of a medical school: standards for accreditation of medical education programs leading to the M.D. degree. Washington DC: LCME; 2010.

22.ACGME outcome project 2000 [Internet]. 2000 [cited Apr 03, 2013]. Available from: http://www.acgme.org.

23. Irby DM, Hekelman FP. Future directions for research on faculty development. Family Medicine. 1997;29:287-9.

24. Hoyert DL. Medical and life-style risk factors affecting fetal mortality, 1989-90: vital health statistics. Hyattsville, MD: NCHS; 1996. 1-32 p.

25. Crawley LM, Marshall PA, Lo B, Koenig BA, End-of-Life Care Consensus $P$. Strategies for culturally effective end-of-life care. Annal Intern Med. 2002;136(9):673-9. 
26. Satterfield JM, Mitteness LS, Tervalon M, Adler N. Integrating the social and behavioral sciences in an undergraduate medical curriculum: the UCSF essential core. Acad Med. 2004;79(1):6-15.

27. America loMCoQoHCi. Crossing the quality chasm: a new health system for the 21st century: National Academy Press; 2001.

28. Knebel E, Greiner AC. Health Professions Education: A Bridge to Quality: National Academies Press; 2003.

29. Coulehan J, Belling C, Williams PC, Van McCrary S, Vetrano M. Human contexts: medicine in society at Stony Brook University School of Medicine. Acad Med. 2003;78(10):987-92.

30. Schroeder SA, Zones JS, Showstack JA. Academic medicine as a public trust. J Am Med Assoc. 1989;262(6):803-12.

31. Bellini LM, Baime M, Shea JA. Variation of mood and empathy during internship. J Am Med Assoc. 2002;287(23):3143-6.

32.Zinn WM, Sullivan AM, Zotov N, Peters AS, Connelly MT, Singer JD, et al. The effect of medical education on primary care orientation: results of two national surveys of students' and residents' perspectives. Acad Med. 2001;76(4):355-65.

33.Gal M, Borg V, Gal J. Qualitative and quantitative research methods in education and psychology. Tehran: SAMT; 2004.

34. Andersen BL. Biobehavioral outcomes following psychological interventions for cancer patients. J Consul Clin Psychol. 2002;70(3):590.

35.Smith TW, Ruiz JM. Psychosocial influences on the development and course of coronary heart disease: current status and implications for research and practice. J Consul Clin Psychol. 2002;70(3):548. 